\title{
Role of occupational therapy in rehabilitation of cancer patients
}

\author{
CIUBEAN Alina Deniza ${ }^{1}$, CIORTEA Viorela Mihaela ${ }^{1,2}$, UNGUR Rodica Ana ${ }^{1,2}$, \\ BORDA Ileana Monica ${ }^{1,2}$, POPA Theodor ${ }^{2}$, IRSAY Laszlo ${ }^{1,2}$
}

Editor: Constantin MUNTEANU, E-mail: office@bioclima.ro

Corresponding author: CIORTEA Viorela Mihaela, E-mail: viorela.ciortea@yahoo.com

1. Department of Rehabilitation, University of Medicine and Pharmacy "Iuliu Hatieganu”, Cluj-Napoca, Romania

2. Department of Rehabilitation, Clinical Rehabilitation Hospital, Cluj-Napoca, Romania

\begin{abstract}
Background. Most adult cancer survivors report a significant decrease of their quality of life and limitations in performing activities of daily living. Occupational therapy is a form of rehabilitation treatment that uses certain techniques and tools aimed at improving functional capacity, improve social participation and overall quality of life. Objective. The overall purpose of this narrative review is to provide a better understanding of the role that occupational therapy can play in the rehabilitation of cancer patients with a focus on the most important cancer-related aspects amenable and manageable by occupational therapy interventions and to increase awareness regarding this form of rehabilitation.

Discussion. Given the fact that there is constant grow in the number of cancer survivors with complex needs, rehabilitation and occupational therapy strategies can increase functionality and health-related quality of life of patients with cancer at any point of the disease, but it remains underused, due to certain barriers.

Conclusions. Occupational therapy, as part of cancer rehabilitation therapy, can lead to improvements in both short and longterm outcomes, while being cost-effective as goals are always set in collaboration with the patients and are aimed to identify and improve the activities most important and relevant for them.
\end{abstract}

Keywords: occupational therapy, cancer, rehabilitation, activities of daily living, quality of life,

\section{INTRODUCTION}

Most adult cancer survivors report a significant decrease of their quality of life (QoL) and limitations in performing basic activities of daily living (ADLs) and/or instrumental activities of daily living (IADLs), some that are due the cancer itself, while some are the result of treatment-related side effects or age-related functional decline. Overall, a cancer patient has a higher risk of developing a long-term disability and is more susceptible to institutionalization and has an increased mortality risk (1-3).

Occupational therapy (OT) is a form of rehabilitation treatment that uses certain techniques and tools aimed at improving functional capacity. Moreover, the OT plan is strictly directed towards the patients' own needs and goals, and it only targets the activities that are most important to his/her well-being and QoL (4).

The most important objectives of the OT interventions are to increase functional status, decrease risk of falling, improve social participation, increase life satisfaction and participation in one's life roles, pain control, improve mental health and overall QoL. Also, another important nuance that is worth mentioning is that it can lead to improvements in both short and long-term outcomes while being also cost-effective as goals are always formulated in collaboration with the patient and are aimed to identify and improve the activities most important to their own specific QoL (5).

The first question that arises can be summarized as follows: "Do cancer patients need rehabilitation interventions?". The answer is quite simple. It is a known fact that many cancer survivors live with considerable disability and sometimes long-lasting effects of the oncological treatment. For example, Gordon et al (2008) showed that in a population of Australian adults with colorectal cancer, $33 \%$ of the men and $40 \%$ of women were not able to return to work 12 months after their diagnosis (6). Moreover, Yuen et al. (2007) reported that $67.5 \%$ of cancer surviving patients stopped driving during treatment while $26.5 \%$ did not resume driving even after finishing the therapy (7).

Even though OT interventions can play an important role in the rehabilitation of cancer patients, another question that arises is: "Why don't we use OT more often as a complementary treatment in cancer patients?". The answer to this question lies in the barriers that stand among us. When talking about barriers, it is safe to assume that these are present on both sides, meaning that both the patient and the rehabilitation specialist have certain difficulties in interacting. 
For the rehabilitation specialists, the barriers could include very little training in the so-called subcategory of oncology rehabilitation, as it is a known fact that without specific training in the field of oncology rehabilitation, it can be challenging to become skilled and effective (8). Another barrier could be the sometimes nonexistent or often weak link between oncology specialists and rehabilitation specialists. These departments are often situated in separate hospital settings and may not be near each other, making it more difficult for the two medical specialties to interact or to identify cancer patients with rehabilitation needs $(9,10)$.

From the cancer patients' perspective, the main barriers he/she meets in order to receive rehabilitation and/or OT support could be a poor awareness of this type of treatment, lack of knowledge of whom OT would benefit, and, probably the most important, limited accessibility to this type of service (11).

OT is a supportive service that has a specific goal, which is to help people functionally engage in every-day life as safely and independently as possible. Unfortunately, for people with cancer, OT interventions are not widely used. Adults with an oncological pathology are at risk for functional decline, which can lead to increased hospitalization, poor tolerance to cancer therapies, and increased health-care costs (12).

\section{Objective}

The overall purpose of this narrative review is to provide a better understanding of the role that OT can play in the rehabilitation of cancer patients with a focus on the most important cancer-related aspects amenable and manageable by OT interventions. Given the fact that there is constant grow in the number of cancer survivors with complex needs, rehabilitation and OT strategies can increase functionality and QoL of patients with cancer at any point of the disease, but it remains underused. It was previously reported that less than $30 \%$ of women with advanced breast cancer who had functional impairment received rehabilitation services, and that only $9 \%$ of older adults with cancer used OT, despite having a modifiable functional limitation $(5,13)$.

\section{Discussion}

The key concepts for OT in cancer patients can be summarized in four words: prevention, restoration, support and palliation (14-16).

Prevention should be aimed at improvement in cardiorespiratory health, musculoskeletal function and balance, cognitive behavioral strategies to reduce anxiety, sleep hygiene, optimization of surgical outcomes, modification of risk factors, nutritional assessment, strategies to return to school, work, or home with adaptive equipment and structural modifications $(9,17,18)$.
Restoration phase is destined for patients who are expected to recover completely and should focus on the return to normal functioning without the need for adaptive equipment or techniques $\left({ }^{1} 9\right)$. Restoration phase is usually multimodal and includes early mobilization, physical therapy in different forms, breathing exercises, relaxation techniques and lymphoedema therapy $(20,21)$.

Supportive goals become the focus of OT interventions when the patient is not able to resume independent ADLs or IADLs and the interventions are designed to teach patients to accommodate to the disability and minimize the changes occurring from the ongoing disease (22). For example, a patient who has lost intrinsic hand function may still become independent if a wrist support, tenodesis splint and adaptive devices are prescribed.

During palliation stage, OT interventions should be focused on improving QoL physically, psychologically and socially, to alleviate symptoms, such as pain, dyspnea, fatigue, nausea, edema and prevent contractures or decubitus ulcers, all while respecting the wishes of the terminal stage patient (17). The OT specialist should provide the patient with assistive devices in order for him to gain control over the environment and to perform any activity that is relevant and important to him/her, while training positioning, breathing and relaxation techniques (23).

Overall, the most common symptoms that a cancer patient or a cancer survivor patient faces are pain and musculoskeletal disorders, deconditioning, fatigue, cognitive impairment, balance issues and risk of falls, lymphoedema and chemotherapy-induced polyneuropathy, all entities that decrease QoL and limit the performance of ADLs or IADLs. Moreover, specific cancer treatment can have a functional impact. For example, side effects of chemotherapy include neutropenia, thrombocytopenia or anemia, which can lead to fatigue, decreased activity tolerance and shortness of breath $(24,25)$. Alongside other therapies to relieve these symptoms, rehabilitation in any form should and can play an important role.

\section{Pain and musculoskeletal disorders}

Many cancer survivors experience either chronic or recurrent pain. Cancer-related pain can arise from residual tissue damage from the cancer and/or its treatment (26). The origin of the pain needs to be assessed, as it can emerge from either muscle complications (contractures), skeletal complications (compression fractures, osteonecrosis), or neuropathic pain (nerve compression, chemotherapy-induced peripheral neuropathy). Each type of pain has different pharmacological management guidelines, indications, contraindications, and thus, the evaluation process is the most important in order to determine the best course of therapy $(27,28)$. 
Alongside pain, there are also other musculoskeletal issues that can occur in a cancer patient, like the upper limb disability found in many breast cancer survivors. Approximately $50 \%$ of women that underwent surgery for breast cancer have limited range-of-motion on the surgical side, associated or not with lymphedema, pain or numbness that leads to impairments in performing ADLs and IADLs, such as putting on a sweater, making the bed, shopping for groceries, or lifting anything weighing more than 5 kilograms, which can be challenging for a young mother to not be able to carry her baby or toddler (29).

OT interventions for patients with limitations in their arms should include a combination of exercise aimed at improving range of motion and muscle strength, stretching, specific training focused on performing limited functional tasks and providing tools and ways of adapting the activity or environment to improve independence $(5,30)$. In addition to this, the timing of exercise implementation is essential, as the outcome is better if therapy is started earlier, as well as the type of exercise, since gradual intensity weight training, with slow progression, better improved upper and lower limb strength, with no negative effects on lymphoedema, if present $\left({ }^{3} 1,32\right)$.

\section{Deconditioning and Endurance Deficits}

Often, cancer patients deal with an overall decline in exercise capacity, while multiple mechanisms can be responsible for decreased exercise tolerance and reduced cardiorespiratory fitness. One classic example is removal of lung tissue that directly impacts exercise tolerance by limiting oxygen diffusing capacity. Also, indirectly, radiation therapy involving the chest wall, with the adverse effect of excessive fibrosis forming, or pharmacologic management of cancers can impact the exercise tolerance. For example, women treated with doxorubicin can develop cardiac complications and might not be able to exercise or might need to have specific monitoring and restrictions, which is why reconditioning should be done gradually (33). Regardless of this, exercise training has been shown to improve exercise capacity in cancer survivors without notable adverse events $(34,35)$.

Rehabilitation specialists and OT specialists should be aware of these aspects and should closely monitor the patient, due to reduced tolerance to exercise, altered baseline vital signs, and altered physiological responses to certain interventions: excessive fatigue, sweating, pallor changes with exercise or activity, and severe shortness of breath (36).

Also, due to the low adherence rate to exercise for cancer survivors than in the general population, OT interventions should also aim at informing and educating the patients as to the benefits of a regular exercise program: better overall health, prevention of heart disease and diabetes, strength, endurance, psychological benefits and better QoL (37-39).

\section{Fatigue}

Cancer-related fatigue is a symptom experienced by most patients who receive treatment for cancer, in many cases it does not resolve upon finishing cancer-specific therapies and is mainly characterized by the fact that is not relieved with rest and is not related to the amount of activity. Moreover, The National Comprehensive Cancer Network (NCCN) defines it as a "distressing persistent, subjective sense of tiredness or exhaustion related to cancer or cancer treatment that is not proportional to recent activity and interferes with usual functioning"(40,41).

In a study conducted by Curt et al (2000), 91\% of adults with cancer reported that fatigue has "prevented them from leading a 'normal' life", while $88 \%$ had to modify their daily routine (42).

Patients dealing with fatigue can benefit from OT interventions, as they can be taught energy conservation techniques, strategies to manage fatigue for them to be able to perform their occupational roles and daily routines (43).

The main OT interventions should include activity modification, prioritization, pacing and delegating activities, task-based activity and energy patterns, alongside personalized adjustments to conserve energy (e.g., placing frequently used objects in the refrigerator at easy-to-reach heights, timing any activities that can increase fatigue and distance them accordingly). In addition, daily self-monitoring of fatigue levels may also help patients find a balance between activity and rest, which works best for them based on their pattern of fatigue $(5,44$.)

\section{Balance and falls}

Cancer survivors often have an increased risk of fall and subsequently, fall-related fractures. This is due to the presence of multiple risk factors, like decreased lower limb strength, decreased sensation and reflexes because of chemotherapy-induced peripheral neuropathy, decreased static and dynamic balance control, osteopenia or osteoporosis (44-47). Because sometimes balance disorders are subtle, it is important to evaluate and measure postural control in multiple challenging positions in order to detect deficits and the rehabilitation specialists need to be able to recognize a postural instability and balance issues in a patient (48).

For fall prevention, the most important OT interventions should include home modifications and adaptations, like grab bars in the tub or shower to help getting in and out of the bath or near the toilet to assist with rising from a sitting to a standing, stair handrails, removal of hazardous objects and use of nonslip mats $(49,50)$. 


\section{Cognitive Function Impairment}

Cancer-related cognitive impairment, also known as chemobrain, is as common side effect of cancer treatment and its defined as difficulties related to memory, attention, processing information and organization.(51). Even mild chemobrain symptoms can have a significant impact on the daily functioning of an individual, resulting in changes to their health status, occupational performance and overall wellbeing (52).

Player et al (2014) reported that women with breast cancer have mild cognitive decline that impacts their ability to function and perform easy activities leading to a loss of independent participation in their family life role. Most patients experiencing chemobrain feel frustration and deal with challenges in participating in occupations that were meaningful to them before, like work, driving, caring for their families, socializing and being able to organize their lives (53).

Certain cognitive strategies can be taught by OT specialists, interventions that are aimed at adapting or remediating the functional impairment: compensating while performing certain tasks or restorative activities during the performance of specific tasks. The OT specialist should advise and help the patient to create an individualized system for: reminders for medications, schedule appointments, to-do type tasks for shopping, cooking or money management. Also, retraining on the use of maps and/or global positioning system devices to stimulate independence should be included on certain cases (5).

\section{Lymphoedema}

Lymphoedema is defined as a chronic swelling due to the tissue accumulation of protein-rich fluid that is not able to drain via the lymphatic system. It can be disfiguring, and although it usually affects one or more limbs, it may involve the trunk, head or genital area (54). Additionally, is an important factor of decreased QoL, altered body image, decreased work/leisure participation and impaired occupational roles (55). Treatment of lymphoedema aims to reduce the size of the involved limb and an effective intervention requires a combination of treatments that includes manual lymph drainage, external compression, exercise, skin care and education (56).

Management of lymphoedema by OT specialist should include patient education in regard of avoiding activities that may exacerbate the swelling and task-specific activity modifications, exercise, energy conservation techniques, auto-massage, correct choice and use of compression garments and swelling management with complete decongestive therapy. Also, OT can help patients identify meaningful activities and implement activity modifications for successful completion, use stress management and relaxation techniques to decrease anxiety, and address any concerns related to changes in body image $(5,57,58$. $)$

\section{Chemotherapy-induced peripheral neuropathy}

Certain chemoterapy pharmacological agents have as side effect the occurrence of peripheral neuropathy, characterized by symptoms like weakness, numbness, tingling and pain in their extremities, that can alter the functional capacity of the individual (59) . Beijers et al (2014) reported that cancer patients with peripheral neuropathy experience difficulties in performing ADLs or IADls, distinguishing items in their hands, and a decrease in overall functional independence $\left({ }^{6} 0\right)$.

OT interventions should be aimed at adapting sensory and functional activities (e.g., cooking) and prescribing specific assistive devices and tools to maintain independence with ADLs and IADLs (e.g., a button hook to assist with fastening buttons when dressing). Overall, OT specialists should address the clinical signs experienced by the patient while providing solutions for performing ADLs safely. For example, numbness can be translated as a functional problem by loss of sharp and dull perception, which increases the risk for cutting and burning during household chores, and an OT solution could be training to use vision, cueing and adapted equipment (61).

\section{Conclusions}

In conclusion, OT specialists should and can address cancer-specific issues that affect the functional status and daily routines of an individual. OT interventions can be tailored to treat several functional deficits and has the potential to limit and reverse cancer-related disability.

The interventions should be aimed at improving the simple skills (e.g.dressing, bathing, using the toilet etc), and also the more complex IADLs (e.g. schedule organization, cooking, being able to care for children or relatives), which will impact in a positive manner the patients' QoL.

\section{References}

1. American Occupational Therapy Association. Standards of practice for occupational therapy. American Journal of Occupational Therapy. 2015;69(6913410057).

2. Hewitt M, Rowland JH, Yancik R. Cancer survivors in the United States: age, health, and disability. The Journals of Gerontology Series A: Biological Sciences and Medical Sciences. 2003 Jan 1;58(1):M82-91.

3. Palmadottir G. The role of occupational participation and environment among Icelandic women with breast cancer: A qualitative study. Scandinavian Journal of Occupational Therapy. 2010 Dec 1;17(4):299-307.

4. Clark F, Azen SP, Zemke R, Jackson J, Carlson M, Mandel D, Hay J, Josephson K, Cherry B, Hessel C, Palmer J. Occupational therapy for independent-living older adults: A randomized controlled trial. Jama. 1997 Oct 22;278(16):1321-6.

5. Pergolotti M, Williams GR, Campbell C, Munoz LA, Muss HB. Occupational therapy for adults with cancer: why it matters. The Oncologist. 2016 Mar;21(3):314. 
6. Gordon L, Lynch BM, Newman B. Transitions in work participation after a diagnosis of colorectal cancer. Australian and New Zealand journal of public health. 2008 Dec;32(6):569-74.

7. Yuen HK, Gillespie MB, Day TA, Morgan L, Burik JK. Driving behaviors in patients with head and neck cancer during and after cancer treatment: a preliminary report. Head \& Neck: Journal for the Sciences and Specialties of the Head and Neck. 2007 Jul;29(7):675-81.

8. Stubblefield MD. The underutilization of rehabilitation to treat physical impairments in breast cancer survivors. PM\&R. 2017 Sep 1;9(9):S317-23.

9. Halkett GK, Ciccarelli M, Keesing S, Aoun S. Occupational therapy in palliative care: Is it under-utilised in Western Australia?. Australian Occupational Therapy Journal. 2010 Oct;57(5):301-9.

10. Silver JK, Gilchrist LS. Cancer rehabilitation with a focus on evidence-based outpatient physical and occupational therapy interventions. American journal of physical medicine \& rehabilitation. 2011 May 1;90(5):S5-15.

11. Kealey P, McIntyre I. An evaluation of the domiciliary occupational therapy service in palliative cancer care in a community trust: a patient and carers perspective. European journal of cancer care. $2005 \mathrm{Jul} ; 14(3): 232-43$.

12. Pergolotti M, Deal AM, Lavery J, Reeve BB, Muss HB. The prevalence of potentially modifiable functional deficits and the subsequent use of occupational and physical therapy by older adults with cancer. Journal of geriatric oncology. 2015 May 1;6(3):194-201.

13. Cheville AL, Troxel AB, Basford JR, Kornblith AB. Prevalence and treatment patterns of physical impairments in patients with metastatic breast cancer. Journal of clinical oncology: official journal of the American Society of Clinical Oncology. 2008 Jun 1;26(16):2621.

14. Dietz JH. Rehabilitation of the cancer patient: its role in the scheme of comprehensive care. Clinical bulletin. 1974;4(3):104.

15. Kurtzman SH, Gardner B, Kellner WS. Rehabilitation of the cancer patient. The American journal of surgery. 1988 Jun 1;155(6):791-803.

16. IJsbrandy C, Ottevanger PB, Gerritsen WR, van Harten WH, Hermens RP. Determinants of adherence to physical cancer rehabilitation guidelines among cancer patients and cancer centers: a cross-sectional observational study. Journal of Cancer Survivorship. 2020 Sep 28:1-5.

17. Margary CJ: Aspects of psychiatric management of breast cancer, Med J Aust 148(5):239-242, 1988.

18. Beauchamp MK, O'Hoski S, Goldstein RS, Brooks D. Effect of pulmonary rehabilitation on balance in persons with chronic obstructive pulmonary disease. Archives of physical medicine and rehabilitation. 2010 Sep 1;91(9):1460-5.

19. Chowdhury RA, Brennan FP, Gardiner MD. Cancer Rehabilitation and Palliative Care-Exploring the Synergies. Journal of Pain and Symptom Management. 2020 Dec 1;60(6):1239-52.

20. Okamura H. Importance of rehabilitation in cancer treatment and palliative medicine. Japanese journal of clinical oncology. 2011 Jun 1;41(6):733-8.
21. Clark MM, Rummans TA, Atherton PJ, Cheville AL, Johnson ME, Frost MH, Miller JJ, Sloan JA, Graszer KM, Haas JG, Hanson JM. Randomized controlled trial of maintaining quality of life during radiotherapy for advanced cancer. Cancer. 2013 Feb 15;119(4):880-7.

22. Rummans TA, Clark MM, Sloan JA, Frost MH, Bostwick JM, Atherton PJ, Johnson ME, Gamble G, Richardson J, Brown P, Martensen J. Impacting quality of life for patients with advanced cancer with a structured multidisciplinary intervention: a randomized controlled trial. Journal of Clinical Oncology. 2006 Feb 1;24(4):635-42.

23. Troeschel AN, Leach CR, Shuval K, Stein KD, Patel AV. Peer Reviewed: Physical Activity in Cancer Survivors During "Re-Entry" Following Cancer Treatment. Preventing chronic disease. 2018;15.

24. Lyons KD, Padgett LS, Marshall TF, Greer JA, Silver JK, Raj VS, Zucker DS, Fu JB, Pergolotti M, Sleight AG, Alfano CM. Follow the trail: Using insights from the growth of palliative care to propose a roadmap for cancer rehabilitation. CA: a cancer journal for clinicians. 2019 Mar;69(2):113-26.

25. Shi Q, Smith TG, Michonski JD, Stein KD, Kaw C, Cleeland CS. Symptom burden in cancer survivors 1 year after diagnosis: a report from the American Cancer Society's Studies of Cancer Survivors. Cancer. 2011 Jun 15;117(12):2779-90.

26. Barsevick AM. The concept of symptom cluster. InSeminars in oncology nursing 2007 May 1 (Vol. 23, No. 2, pp. 89-98). WB Saunders.

27. Mao JJ, Armstrong K, Bowman MA, Xie SX, Kadakia R, Farrar JT. Symptom burden among cancer survivors: impact of age and comorbidity. The Journal of the American Board of Family Medicine. 2007 Sep $1 ; 20(5): 434-43$.

28. Bennett MI, Rayment C, Hjermstad M, Aass N, Caraceni A, Kaasa S. Prevalence and aetiology of neuropathic pain in cancer patients: a systematic review. Pain. 2012 Feb 1;153(2):359-65.

29. Kwan W, Towers A. Arm morbidity and disability after breast cancer: new directions for care. InOncology nursing forum 2008 (Vol. 35, No. 1, p. 65). Oncology Nursing Society.

30. Kwan W, Towers A. Arm morbidity and disability after breast cancer: new directions for care. InOncology nursing forum 2008 (Vol. 35, No. 1, p. 65). Oncology Nursing Society.

31. Chan DN, Lui LY, So WK. Effectiveness of exercise programmes on shoulder mobility and lymphoedema after axillary lymph node dissection for breast cancer: systematic review. Journal of Advanced Nursing. 2010 Sep;66(9):1902-14.

32. McNeely ML, Campbell K, Ospina M, Rowe BH, Dabbs K, Klassen TP, Mackey J, Courneya K. Exercise interventions for upper-limb dysfunction due to breast cancer treatment. Cochrane Database of Systematic Reviews. 2010(6).

33. Paramanandam VS, Roberts D. Weight training is not harmful for women with breast cancer-related lymphoedema: a systematic review. Journal of physiotherapy. 2014 Sep 1;60(3):136-43. 
34. Daley AJ, Crank H, Mutrie N, Saxton JM, Coleman R. Patient recruitment into a randomised controlled trial of supervised exercise therapy in sedentary women treated for breast cancer. Contemporary clinical trials. 2007 Sep 1;28(5):603-13.

35. Jones LW, Eves ND, Haykowsky M, Freedland SJ, Mackey JR. Exercise intolerance in cancer and the role of exercise therapy to reverse dysfunction. The lancet oncology. 2009 Jun 1;10(6):598-605.

36. Courneya KS, McKenzie DC, Mackey JR, Gelmon K, Reid RD, Friedenreich CM, Ladha AB, Proulx C, Vallance JK, Lane K, Yasui Y. Moderators of the effects of exercise training in breast cancer patients receiving chemotherapy: a randomized controlled trial. Cancer: Interdisciplinary International Journal of the American Cancer Society. 2008 Apr 15;112(8):1845-53.

37. Maltser S, Cristian A, Silver JK, Morris GS, Stout NL. A focused review of safety considerations in cancer rehabilitation. PM\&R. 2017 Sep 1;9(9):S415-28.

38. Schwartz AL, Mori MO, Gao RE, NAIL LM, KING ME. Exercise reduces daily fatigue in women with breast cancer receiving chemotherapy. Medicine \& Science in Sports \& Exercise. 2001 May 1;33(5):718-23.

39. Pinto BM, Trunzo JJ. Body esteem and mood among sedentary and active breast cancer survivors. InMayo Clinic Proceedings 2004 Feb 1 (Vol. 79, No. 2, pp. 181-186). Elsevier.

40. Nikander R, Sievänen H, Ojala K, Oivanen T, KellokumpuLehtinen PL, Saarto T. Effect of a vigorous aerobic regimen on physical performance in breast cancer patients-a randomized controlled pilot trial. Acta Oncologica. 2007 Jan 1;46(2):181-6.

41. Salca A, Checiches A, Irsay L. The Approach of Cancer Related Fatigue in Rehabilitation Medicine: Part Imechanisms, symptoms, clinical evaluation and screening. BALNEO RESEARCH JOURNAL. 2015 May 1;6(2):7985.

42. Salca A, Checiches A, Irsay L. The approach of cancer related fatigue in rehabilitation medicine: Part IITherapeutic interventions. Balneo Research Journal. 2015 Sep 1;6(3):140-2.

43. Curt GA, Breitbart W, Cella D, Groopman JE, Horning SJ, Itri LM, Johnson DH, Miaskowski C, Scherr SL, Portenoy RK, Vogelzang NJ. Impact of cancer-related fatigue on the lives of patients: new findings from the Fatigue Coalition. The oncologist. 2000 Oct 1;5(5):353-60.

44. Vockins H. Occupational therapy intervention with patients with breast cancer: a survey. European journal of cancer care. 2004 Mar;13(1):45-52.

45. Koornstra RH, Peters M, Donofrio S, van den Borne B, de Jong FA. Management of fatigue in patients with cancer-a practical overview. Cancer Treatment Reviews. 2014 Jul 1;40(6):791-9.

46. Simmonds MJ. Physical function in patients with cancer: psychometric characteristics and clinical usefulness of a physical performance test battery. Journal of pain and symptom management. 2002 Oct 1;24(4):404-14.

47. Wampler MA, Topp KS, Miaskowski C, Byl NN, Rugo HS, Hamel K. Quantitative and clinical description of postural instability in women with breast cancer treated with taxane chemotherapy. Archives of physical medicine and rehabilitation. 2007 Aug 1;88(8):1002-8.

48. Markman M. Chemotherapy-induced peripheral neuropathy: underreported and underappreciated. Current pain and headache reports. 2006 Aug 1;10(4):275-8.

49. Gilchrist LS, Galantino ML, Wampler M, Marchese VG, Morris GS, Ness KK. A framework for assessment in oncology rehabilitation. Physical Therapy. 2009 Mar 1;89(3):286-306.

50. Clemson L, Mackenzie L, Ballinger C, Close JC, Cumming RG. Environmental interventions to prevent falls in community-dwelling older people: a meta-analysis of randomized trials. Journal of Aging and Health. 2008 Dec;20(8):954-71.

51. Harvey LA, Mitchell RJ, Lord SR, Close JC. Determinants of uptake of home modifications and exercise to prevent falls in community-dwelling older people. Australian and New Zealand journal of public health. 2014 Dec;38(6):58590.

52. Asher A. Cognitive dysfunction among cancer survivors. American journal of physical medicine \& rehabilitation. 2011 May 1;90(5):S16-26.

53. Brezden CB, Phillips KA, Abdolell M, Bunston T, Tannock IF. Cognitive function in breast cancer patients receiving adjuvant chemotherapy. Journal of Clinical Oncology. 2000 Jul 14;18(14):2695-701.

54. Player L, Mackenzie L, Willis K, Loh SY. Women's experiences of cognitive changes or 'chemobrain' following treatment for breast cancer: A role for occupational therapy?. Australian Occupational Therapy Journal. 2014 Aug;61(4):230-40.

55. Morgan PA, Franks PJ, Moffatt CJ. Health-related quality of life with lymphoedema: a review of the literature. International wound journal. 2005 Mar;2(1):47-62.

56. Shigaki CL, Madsen R, Wanchai A, Stewart BR, Armer JM. Upper extremity lymphedema: Presence and effect on functioning five years after breast cancer treatment. Rehabilitation Psychology. 2013 Nov;58(4):342.

57. Collard V. Understanding lymphoedema and the occupational therapist's role. Australian Occupational Therapy Journal. 1990 Jun;37(2):109-11.

58. Moffatt CJ, Franks PJ, Doherty DC, Williams AF, Badger C, Jeffs E, Bosanquet N, Mortimer PS. Lymphoedema: an underestimated health problem. Qjm. 2003 Oct 1;96(10):731-8.

59. Kärki A, Anttila H, Tasmuth T, Rautakorpi UM. Lymphoedema therapy in breast cancer patients-a systematic review on effectiveness and a survey of current practices and costs in Finland. Acta oncologica. 2009 Jan 1;48(6):850-9.

60. Speck RM, DeMichele A, Farrar JT, Hennessy S, Mao JJ, Stineman MG, Barg FK. Scope of symptoms and selfmanagement strategies for chemotherapy-induced peripheral neuropathy in breast cancer patients. Supportive Care in Cancer. 2012 Oct 1;20(10):2433-9.

61. Beijers A, Mols F, Dercksen W, Driessen C, Vreugdenhil G. Chemotherapy-induced peripheral neuropathy and impact on quality of life 6 months after treatment with chemotherapy. The Journal of community and supportive oncology. 2014 Nov 1;12(11):401-6. 